\title{
Impedance Flow Cytometry for Selection of Pollen Traits Under High Temperature Stress in Pepper
}

\author{
Shih-wen Lin and Tsung-han Lin \\ World Vegetable Center, Shanhua, Tainan, Taiwan 74151
}

Cynthia Kung Man Yee

Faculty of Sustainable Agriculture, Universiti Malaysia Sabah, Kota Kinabalu, Sabah, Malaysia 88400

\section{Joyce Chen}

School of Agriculture and Food Sciences, University of Queensland, St. Lucia, Brisbane, Australia 4067

Yen-wei Wang

World Vegetable Center, Shanhua, Tainan, Taiwan 74151

\author{
Manoj Kumar Nalla \\ World Vegetable Center, South and Central Asia Regional Office, Patancheru, \\ Hyderabad, India 502324
}

\section{Derek W. Barchenger \\ World Vegetable Center, Shanhua, Tainan, Taiwan 74151}

Additional index words. Capsicum annuum, chile pepper, heat tolerance, pollen viability

\begin{abstract}
High temperature stress is a major limiting factor for pepper productivity, which will continue to be a problem under climate change scenarios. Developing heat tolerant cultivars is critical for sustained pepper production, especially in tropical and subtropical regions. In fruiting crops, like pepper, reproductive tissues, especially pollen, are the most sensitive to high temperature stress. Typically, pollen viability and germination are assessed through staining and microscopy, which is tedious and potentially inaccurate. To increase efficiency in assessing pollen traits of pepper, the use of impedance flow cytometry (IFC) has been proposed. We conducted three independent experiments to determine the most effective methodology to use IFC for evaluating pollen traits for heat tolerance in pepper. Seven floral developmental stages were evaluated, and stages 3,4 , and 5 were found to best combine high pollen concentration and activity. Flowers in development stages 3,4 , or 5 were then heat treated at 41, 44, 47, 50, and $55{ }^{\circ} \mathrm{C}$ or not heat treated (control). The critical temperature to assess heat tolerance using IFC was found to be $50^{\circ} \mathrm{C}$, with a reduction in pollen activity and concentration occurring at temperatures greater than $47^{\circ} \mathrm{C}$. Twenty-one entries of pepper were then accessed for pollen traits using the staining and IFC methods over 2 months, April (cooler) and June (hotter). Growing environment was found to be the greatest contributor to variability for nearly all pollen traits assessed, with performance during June nearly always being lower. PBC 507 and PBC 831 were identified as being new sources of heat tolerance, based on using IFC for assessing pollen. Pollen viability determined by staining and pollen activity determined using IFC were significantly positively correlated, indicating that IFC is an efficient and accurate method to assess pollen traits in pepper. This work provides a basis for further research in this area and supports more efficient breeding of heat-tolerant cultivars.
\end{abstract}

Pepper (Capsicum annuum) is one of the most important spice and vegetable crops worldwide (Bosland and Votava, 2012). Consumer demand for pepper has substantially increased over the past 30 years, especially for hot chile pepper. It has been estimated that peppers are consumed daily by about a quarter of the world's population (Halikowski-Smith, 2015). Global production of pepper was 42.3 million tonnes on an area of 3.7 million hectares in 2019 and $\approx 60 \%$ of pepper is produced in Asia (Food and Agriculture Organization of the United Nations, 2019). The primary limitations to increased pepper productivity and quality are biotic and abiotic stresses. The major abiotic stresses limiting pepper productivity in tropical and subtropical regions include high temperature and flooding. The base growingdegree-days temperature for pepper is $18^{\circ} \mathrm{C}$ with lower temperatures resulting in negligible growth (Sanders et al., 1980). Higher yields occur when daily air temperature ranges between 18 and $32^{\circ} \mathrm{C}$ during fruit set. In response to high temperature, peppers tend to abort reproductive organs (buds, flowers, and young fruits), and cyclical fluctuations occur in fruit set. Stages susceptible to abortion are very young buds ( $<2.5 \mathrm{~mm}$ ), buds close to anthesis, and flowers and fruits up to $14 \mathrm{~d}$ after anthesis. The strong influence of temperature on flower and fruit development in pepper has been widely studied (Aloni et al., 2001; Erikson and Markhart, 2002; Polowick and Sawhney, 1985; Pressman et al., 1998; Wubs et al., 2009).

Harnessing crop tolerance to elevated temperatures is essential for sustaining vegetable production in tropical areas and will become even more important under future climate change scenarios. Pollen is the most heat-susceptible stage in many crop species (Giorno et al., 2013; Hedhly et al., 2009), and without viable pollen, fruit set of pepper and other fruiting vegetables is reduced or completely impeded. Selection of heat-tolerant plants can be done by monitoring fruit set, but this method does not discriminate between the various flower traits involved (pollen viability, pollen germination, stigma exsertion, stigma nonreceptivity, arrested pollen tube growth, or other traits). Furthermore, it requires measuring fruit set over an extended time and is sensitive to variations in temperature that could permit an otherwise heat-sensitive plant to set fruit. Pollen viability is usually monitored by staining the harvested pollen and counting pollen with specific staining patterns under a microscope (Heslop-Harrison et al., 1984). This is a laborious and time-consuming technique with limited throughput.

For crops like pepper, pollen viability alone does not sufficiently inform about the capacity of pollen to fertilize female germ cells. Instead, pollen germination data are required to estimate heat tolerance of pepper pollen (Mercado and Quesadac, 1994). In vitro pollen germination may be affected by genotype-specific differences in compatibility with germination media. Like pollen viability tests, this method is laborious and has low throughput, limiting its usefulness in breeding. There have been reports that IFC is an efficient, label-free, and reliable technique to analyze pollen activity in a species-independent, high-throughput manner (Ascari et al., 2020; Canonge et al., 2020; Heidmann et al., 2016; Heidmann and Di Berardino, 2017; Impe et al., 2020). In IFC, pollen grains in suspension flow through a microchannel, where an alternating electric field is applied between 2 and $12 \mathrm{MHz}$. Each pollen grain changes the measured impedance signal depending on dielectric properties (Sun and Morgan, 2010). At low frequencies, the phospholipid bilayer of the outer membrane becomes polarized, thereby obstructing current flow and acting as a capacitor and allowing for pollen number to be calculated (Azzarello et al., 2012). At intermediate frequencies, membrane polarization decreases, and pollen capacitance and conductance can be characterized, giving information about viability, whereas at higher frequencies, the plasma membrane is no longer an impediment to the electric field, and the cytoplasm and organelle status can be assessed (Cheung et al., 2005). Flow cytometry using fluorescent probes has been used for the evaluation of pollen DNA content in numerous species of plants (Kron and Husband, 2015) and pollen response to temperature stress in arabidopsis (Arabidopsis thaliana L.) and tomato (Solanum lycopersicum L.) (Luria et al., 2019). The use of label-free IFC to study microspore development and characterization of pollen viability pollen has 
been reported in hazelnut (Corylus avellana L.) (Ascari et al., 2020), sweet pepper, tomato, and cucumber (Cucumis sativus L.) (Heidmann et al., 2016) and in wheat (Triticum aestivum L.) (Canonge et al., 2020; Impe et al., 2020). Although protocols have been established for using IFC in numerous crops (Heidmann and Di Berardino, 2017), there is a clear need to evaluate the effectiveness of using IFC to assess pollen traits in pepper and to develop an efficient protocol to improve selection accuracy for heat tolerance.

\section{Materials and Methods}

Establishing a protocol for pollen using impedance flow cytometry. All experiments were conducted at the World Vegetable Center, Shanhua, Tainan, Taiwan (lat. $23.1^{\circ} \mathrm{N}$, long. $120.3^{\circ} \mathrm{E}$, elevation $12 \mathrm{~m}$ ). Before sowing, all seed was treated with trisodium phosphate (TSP) and hydrochloric acid ( $\mathrm{HCl}$ ) following the methods of Kenyon et al. (2017). To establish an effective protocol for downstream experiments using IFC analysis in pepper, we selected a heat tolerant (9852-123) and a heat sensitive (AVPP9823) breeding line. Seeds were sown into 70-cell plastic trays (Wen-kai Plastic, Nantou, Taiwan) filled with sterilized King Root substrate V008 (Dayi Agritech, Pingtung, Taiwan) and placed in a climate-controlled greenhouse for germination at $28 \pm 3{ }^{\circ} \mathrm{C}$ with a 12 -h photoperiod and $95 \%$ relative humidity $(\mathrm{RH})$. Plants were irrigated twice daily, and after germination, the seedlings were fertilized with Nitrophoska (Incitec Pivot Fertilisers, Victoria, Australia). At the four to six true leaf stage, the seedlings were transplanted into 7-inch pots (Chin-Liang-Fa Gardening Supplies, Tainan, Taiwan) filled with sterilized garden soil and maintained in the climate-controlled greenhouse. At anthesis, we divided the flowers into seven developmental stages, where ST1 were immature small flower buds that were not yet colored, ST2 were larger immature flower buds with nearly completely colored petals, ST3 completely colored mature flower buds, ST4 were open flowers with a low level of visible pollen, ST5 were open flowers with highly visible pollen, ST6 were completely open flowers with copious amounts of pollen, and ST7 were discolored (tan or yellow) flowers (Fig. 1).

Following the manufacturer instructions, two flowers at each stage were collected early

Received for publication 20 Sept. 2021. Accepted for publication 18 Oct. 2021.

Published online 5 January 2022.

Funding for this research was provided in part by the Council of Agriculture of Taiwan (project nos. 108AS1.1.2-ST-a4 and 109AS-1.1.2-ST-a3), the World Vegetable Center Innovations Fund, and the long-term strategic donors to the World Vegetable Center, Taiwan; the U.S. Agency for International Development; UK aid from the UK government; Australian Centre for International Agricultural Research (ACIAR), Germany, Thailand, Philippines, Korea, and Japan.

D.W.B. is the corresponding author. E-mail: derek.barchenger@worldveg.org.

This is an open access article distributed under the CC BY-NC-ND license (https://creativecommons. org/licenses/by-nc-nd/4.0/).

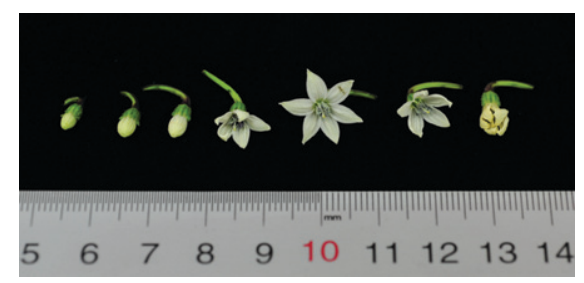

Fig. 1. The seven Capsicum flower developmental stages (ST1 to ST7 from left to right) used for pollen evaluation with impedance flow cytometry, where ST1 were immature small flower buds that were not yet colored, ST2 were larger immature flower buds with nearly completely colored petals, ST3 completely colored mature flower buds, ST4 were open flowers with a low level of visible pollen, ST5 were open flowers with highly visible pollen, ST6 were completely open flowers with copious amounts of pollen, and ST7 were discolored (tan or yellow) flowers.

in the morning, between 8:00 and 9:00 AM. The anthers were removed using forceps and placed into a 1.5-mL Eppendorf tube (Gene Science Enterprise, Kaohsiung, Taiwan). We then added $0.75 \mathrm{~mL}$ of the AmphaFluid 6 (AF6) buffer solution (\#21.006; Amphasys AG, Root, Switzerland) into the tube and suspended the pollen by agitation using a tube rack (Hao-Chi Tech, Tainan, Taiwan) and moving the tube over the length of the tube rack several times. To remove excess debris, the solution was then filtered using $50-\mu \mathrm{m}$ filters (\#22.050, Amphasys AG) into a new tube, and an additional $0.75 \mathrm{~mL}$ of the AF6 buffer was added to the filter. The filtrate was then incubated at room temperature for $2 \mathrm{~min}$ to equilibrate the pollen. The samples were then analyzed using a 120- $\mu$ m AmphaChip (\#11.120, Amphasys AG) through the Ampha Z32 impedance flow cytometer (\#10.032, Amphasys AG) following the manufacturer's instructions. The settings for the analysis were slightly modified to stop the analysis either at 2 min or when 10,000 cells were measured, whichever came first.

The pollen concentration and percent pollen activity were determined using the AmphaSoft software (v.2.0, Amphasys AG). For this, we first removed the small, nonpollen plant cells and debris, which had lower amplitudes compared with pollen grains, from the analysis. Then we partitioned the pollen based on phase angle, where pollen grains with a larger phase angle were considered active, meaning viable pollen grains that are likely to germinate; inactive pollen grains, meaning those that are viable but will not germinate; and inviable pollen grains.

The experimental design was a randomized complete block design with three replications for the two pepper lines. The experimental units were single plants, and blocking was done by bench in the polyhouse. The $\log ^{10}$ transformed percent active pollen and pollen concentration were analyzed using a linear model analysis of variance (ANOVA; $\alpha=$ 0.05 ), and Tukey's honestly significant difference test was used for means separation in R3.6.3 (R Core Team, 2020).
Determining effective heat treatments for screening pollen. To effectively screen for heat tolerance in pepper, in vitro heat treatments are required to ensure sufficient heat stress is imposed, which may not be available in certain growing environments. Five lines (1607-7037-1, AVPP1704, AVPP1708, AVPP1714, and PBC 435 ) were used to evaluate different in vitro heat treatments on pollen viability. The sowing conditions were the same as previously described; however, for this experiment, the plants were grown during the winter season in a polyhouse without climate control.

Flowers in developmental stages ST3, ST4, or ST5 were collected in bulk from the plants within a replication between 8:00 and 9:00 AM and subjected to one of six treatments: either no treatment or heat treatment at 41,44 , 47,50 , or $55^{\circ} \mathrm{C}$. The heat treatments were selected as being $3^{\circ} \mathrm{C}$ higher than the previously reported maximum threshold of fruit set and yield for pepper (Sanders et al., 1980) and, following the method of Heidmann et al. (2016) and Heidmann and Di Berardino (2017), incrementally increased until $55^{\circ} \mathrm{C}$, which was found to induce complete pollen death in preliminary studies (data not shown). Heat treatments were conducted in an incubator (JBL-30; Prosperous Instruments, Chaiyi, Taiwan) in darkness for $1 \mathrm{~h}$. The pollen activity and concentration were then determined using the IFC as previously described.

A split-plot design was followed with three replications, each with five plants, with the split being heat treatment. For analysis, the percent active pollen data were $\log ^{10}$-transformed and then analyzed using ANOVA $(\alpha=0.05)$, and Tukey's honestly significant difference test was used for means separation in R-3.6.3 (R Core Team, 2020).

Validation of established pollen protocols. Through preliminary experimentation screening nearly 500 Capsicum accessions (Lin et al., 2020), we selected 21 entries of pepper, which were either heat tolerant (1607-7093-1, 17377546-1, 1847-7527-1, 1847-7683-1, 99434384-2-2-1-1-1-1, AVPP0303, AVPP0701, AVPP1108, AVPP1322, AVPP1367, AVPP1706, P-AV-01-2, PBC 461, PBC 507, PBC 534, $\mathrm{PBC} 831$, and VI012668) or heat sensitive (AVPP1327, PBC 149, PBC 370, and VI047$123)$ to conduct validation studies of our heat treatment and IFC protocol.

For this experiment, the seedlings were sown and maintained as before, but at the four to six true leaf stage, the plants were transplanted into 7-inch pots filled with sterilized garden soil in a polyhouse without climate control. The plants were maintained throughout the spring and summer seasons to evaluate the effect of the growing environment on pollen viability. During the months of April (cooler) and June (hotter), we measured the pollen concentration and activity using IFC as well as pollen viability and germination as previously described. The bulk harvested flowers were subjected to either heat treatment at 45 or $50^{\circ} \mathrm{C}$ or no heat treatment. The flowers were then divided into two groups for either direct analysis using IFC or 
incubation at $28^{\circ} \mathrm{C}$ for $2 \mathrm{~h}$ followed by viability and germination tests using staining and microscopy as previously described. After heat treatment, the bulked flowers were randomly divided into two groups to be analyzed either using the aforementioned IFC protocol or pollen viability and germination tests by staining. For in vitro pollen staining, a germination solution modified from Reddy and Kakani (2007) was added to a $1.5-\mathrm{mL}$ Eppendorf tube and agitated by hand to release the pollen into solution. Then $35 \mu \mathrm{L}$ of the sample was aliquoted from the tube to a hemocytometer and incubated at $28^{\circ} \mathrm{C}$ for $2 \mathrm{~h}$ in darkness, and $15 \mu \mathrm{L}$ of $1 \%$ aceti-carmine dye [(calcium-aluminum lacquer of carminic acid) Certistain, Merck KGaA, Darmstadt, Germany] was added to each sample and viewed under $40 \times$ magnification (Olympus Taiwan Co. Ltd., Taipei, Taiwan) after the incubation. Tcapture imaging software (Tucsen Photonics, Fujian, China) was used to transmit the reflection from the microscope to the computer screen for further analysis. An area with at least 100 pollen grains was randomly selected to quantify the proportion of inviable, viable but not germinated, and germinated pollen. In addition to pollen tube germination, we also recorded pollen tube length, following the protocol established by Reddy and Kakani (2007).

The temperature and $\mathrm{RH}$ inside the polyhouse were recorded every $15 \mathrm{~min}$ throughout the experimental period using a HOBO data logger (Pro v2 U23; Onset Computer Corporation, Bourne, MA). The HOBO data logger was mounted at approximately the height of a mature pepper plant on the bench $(\approx 1.5 \mathrm{~m}$ above the ground) centrally located in the polyhouse, and to eliminate direct exposure by sunlight, it was mounted inside a plastic container, which was open at the bottom. During April, the average temperature was $25.8^{\circ} \mathrm{C}$ with a range of 13.8 to $40.8^{\circ} \mathrm{C}$ and an average of $68.3 \%$ and a range of $19.8 \%$ to $96.5 \% \mathrm{RH}$. During June, the average temperature was $30.7^{\circ} \mathrm{C}$ with a range of 24.7 to $40.5^{\circ} \mathrm{C}$ and an average RH of $75.9 \%$ and a range of $40.2 \%$ to $99.7 \%$. Between the 2 months, the major difference in temperature was not daily high but daily low, with April having considerably cooler night time temperatures, which is more conducive for fruit set (Sanders et al., 1980)

We used a randomized complete block design for this experiment, with three replications each with three plants, which served as experimental units. The experiment was blocked by polyhouse bench. The percent pollen activity, germination, and viability were $\log ^{10}$ transformed before analysis. Data were analyzed in $\mathrm{R}$ (v.3.6.3) using linear model fit ANOVA ( $\alpha=$ 0.05 ), linear regression, and correlations using Pearson's correlation coefficient.

\section{Results}

Establishing a protocol for pollen using impedance flow cytometry. The more appropriate flower stage to evaluate pollen traits using IFC was determined by testing pollen collected from seven flower stages of two entries. The main effect of flower stage

Table 1. Pollen concentration and pollen activity percentage determined during seven flower development stages in pepper. Values were averaged across two entries of pepper (Capsicum annuum).

\begin{tabular}{lcc}
\hline Flower developmental stage & Pollen concn $($ pollen grains/mL) & Active pollen $(\%)$ \\
\hline ST1 & $8,372 \mathrm{bc}^{\mathrm{z}}$ & $69.7 \mathrm{a}$ \\
ST2 & $2,878 \mathrm{~d}$ & $71.4 \mathrm{a}$ \\
ST3 & $7,836 \mathrm{bcd}$ & $79.3 \mathrm{a}$ \\
ST4 & $11,741 \mathrm{ab}$ & $53.3 \mathrm{ab}$ \\
ST5 & $15,864 \mathrm{a}$ & $52.2 \mathrm{ab}$ \\
ST6 & $9,600 \mathrm{bc}$ & $22.3 \mathrm{~b}$ \\
ST7 & $5,930 \mathrm{~cd}$ & $14.7 \mathrm{c}$ \\
$P$ value & 0.004 & $<0.001$ \\
\hline
\end{tabular}

${ }^{\mathrm{z}}$ Means within a column followed by the same letter do not significantly differ at $\alpha=0.05$ using Tukey's honestly significant difference.

significantly influenced both pollen concentration $(P=0.004)$ and pollen activity $(P \leq$ 0.001 ), whereas the main effect of entry also significantly influenced pollen activity $(P=$ 0.002) (Table 1). The interaction effects of entry by flower stage did not significantly contribute to the variability observed for pollen concentration or activity.

Average pollen contraction in this study was 8889 pollen grains $/ \mathrm{mL}$ (Table 1). Pollen concentration was highest at the ST5 stage, with 15,864 pollen grains $/ \mathrm{mL}$, followed by the ST4 stage with 11,741 pollen grains $/ \mathrm{mL}$. The lowest pollen concentration was observed at the ST2 stage, with 2878 pollen grains $/ \mathrm{mL}$ (Table 1). The average pollen activity across the flower stages was $52 \%$ (Table 1). Pollen activity was highest at ST3 $(79.3 \%)$, ST2 (71.4\%), and ST1 (69.7\%) followed by ST4 (53.3\%) and ST5 (52.2\%) (Table 1). The oldest flower stage, ST7, had the overall lowest pollen activity, at $14.7 \%$ (Table 1). The heat-tolerant entry $9852-123$ had significantly higher pollen activity $(71 \%)$ than the heat sensitive entry AVPP9823 (33\%) (Fig. 2)

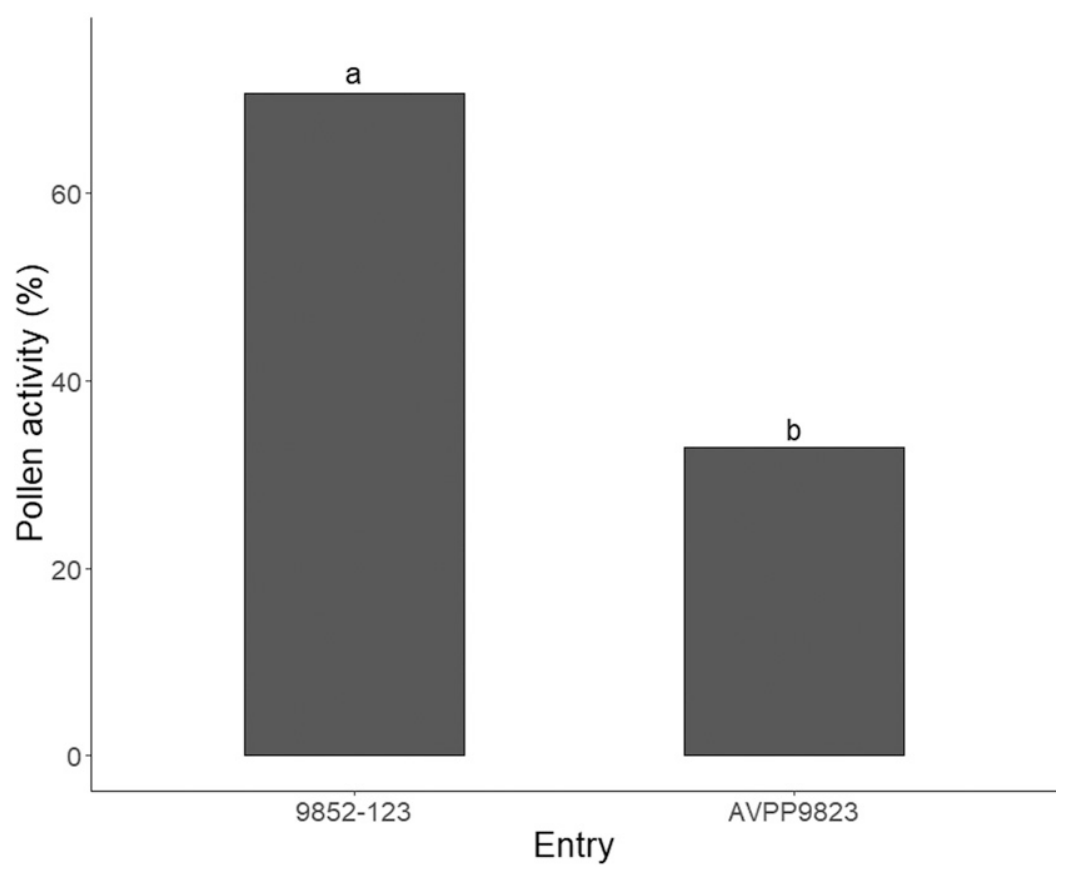

Fig. 2. Pollen activity percentage averaged across the seven flower development stages (ST1-ST7) for two pepper (Capsicum annuum) entries. Bars with the same letter do not significantly differ at $\alpha=$ 0.05 using Tukey's honestly significant difference.
Determining effective heat treatments for screening pollen. To identify the heat treatment best suited for identification of heat tolerance based on pollen traits, we evaluated five entries under untreated or one of five heat treatments $\left(41,44,47,50\right.$, or $\left.55^{\circ} \mathrm{C}\right)$. The main effect of heat treatment significantly contributed to the variability observed in pollen activity $(P<0.001)$, whereas the interaction of entry by heat treatment significantly influenced pollen concentration $(P<$ $0.001)$. Average pollen activity when determining the effect of heat treatment was $72 \%$ (Table 2). The pollen activity under heat treatment at $44^{\circ} \mathrm{C}(83 \%)$ and $47^{\circ} \mathrm{C}(83 \%)$ was not different from the untreated control $(88 \%)$ but was higher than heat treatment at $41^{\circ} \mathrm{C}(82 \%)$ (Table 2$)$. Pollen activity was lowest when treated with $55^{\circ} \mathrm{C}(27 \%)$ and then at $50{ }^{\circ} \mathrm{C}(69 \%)$ (Table 2). The highest pollen concentration was observed for AVPP 1704 heat treated at $55^{\circ} \mathrm{C}$ followed by AVPP1708 heat treated at $47^{\circ} \mathrm{C}$ (Table 3). The entry 1607-7031-1 heat treated at both 41 and $50^{\circ} \mathrm{C}$ and AVPP1704 heat treated at $50^{\circ} \mathrm{C}$ had the lowest pollen concentration 
Table 2. Percent pollen activity of flowers either heat treated at five temperatures or untreated (control). Values averaged over five pepper (Capsicum annuum) entries.

\begin{tabular}{lc}
\hline Heat treatment & Pollen activity (\%) \\
\hline Fresh (untreated) & $88.0 \mathrm{a}^{\mathrm{z}}$ \\
$41^{\circ} \mathrm{C}$ & $81.5 \mathrm{ab}$ \\
$44^{\circ} \mathrm{C}$ & $83.4 \mathrm{a}$ \\
$47^{\circ} \mathrm{C}$ & $82.5 \mathrm{a}$ \\
$50^{\circ} \mathrm{C}$ & $69.2 \mathrm{~b}$ \\
$55^{\circ} \mathrm{C}$ & $27.2 \mathrm{c}$ \\
$P$ value & $<0.001$ \\
\hline${ }^{\mathrm{z}}$ Means within a column followed by the same \\
letter do not significantly differ at $\alpha=0.05$ \\
using Tukey's honestly significant difference.
\end{tabular}

(Table 3). Average pollen concentration across heat treatment and entry was 13,622 pollen grains $/ \mathrm{mL}$ (Table 3 ).

Validation of established pollen protocols. For validation of the protocols established herein, we evaluated the pollen activity, pollen concentration, pollen viability, pollen germination, and pollen tube length of 21 entries, untreated or heat treated at either 45 or $50^{\circ} \mathrm{C}$ during 2 months, April (cooler) and June (hotter). The three-way interaction of entry by treatment by month significantly contributed to the variability observed for pollen germination and pollen tube length. The two-way interactions of month by treatment and entry by month significantly influenced pollen concentration and pollen viability, whereas the two-way interactions of entry by month and entry by treatment

Table 3. Pollen concentration of five pepper (Capsicum annuum) entries treated with one of five heat treatments or an untreated control.

\begin{tabular}{|c|c|c|}
\hline Heat treatment & Entry & Pollen concn (pollen grains $/ \mathrm{mL}$ ) \\
\hline \multirow[t]{5}{*}{ Fresh (untreated) } & $1607-7037-1$ & $10,009 \mathrm{def}^{\mathrm{Z}}$ \\
\hline & AVPP1704 & 19,125 b-e \\
\hline & AVPP1708 & 8,337 ef \\
\hline & AVPP1714 & 16,447 b-e \\
\hline & PBC 435 & 15,107 b-e \\
\hline \multirow[t]{5}{*}{$41^{\circ} \mathrm{C}$} & $1607-7037-1$ & $6,541 \mathrm{f}$ \\
\hline & AVPP1704 & $12,125 \mathrm{~b}-\mathrm{e}$ \\
\hline & AVPP1708 & 15,966 b-e \\
\hline & AVPP1714 & 11,894 c-e \\
\hline & PBC 435 & 18,846 b-e \\
\hline \multirow[t]{5}{*}{$44^{\circ} \mathrm{C}$} & $1607-7037-1$ & $10,556 \mathrm{def}$ \\
\hline & AVPP1704 & 8,548 ef \\
\hline & AVPP1708 & 12,967 b-e \\
\hline & AVPP1714 & 9,782 ef \\
\hline & PBC 435 & $21,391 \mathrm{bcd}$ \\
\hline \multirow[t]{5}{*}{$47^{\circ} \mathrm{C}$} & $1607-7037-1$ & $11,363 \mathrm{def}$ \\
\hline & AVPP1704 & 8,153 ef \\
\hline & AVPP1708 & $24,463 \mathrm{~b}$ \\
\hline & AVPP1714 & 8,307 ef \\
\hline & PBC 435 & 17,708 b-d \\
\hline \multirow[t]{5}{*}{$50^{\circ} \mathrm{C}$} & $1607-7037-1$ & $7,180 \mathrm{f}$ \\
\hline & AVPP1704 & $7,126 \mathrm{f}$ \\
\hline & AVPP1708 & $11,539 \mathrm{c}-\mathrm{e}$ \\
\hline & AVPP1714 & 9,683 ef \\
\hline & PBC 435 & $22,929 \mathrm{bc}$ \\
\hline \multirow[t]{6}{*}{$55^{\circ} \mathrm{C}$} & $1607-7037-1$ & 12,901 b-e \\
\hline & AVPP1704 & $26,810 \mathrm{a}$ \\
\hline & AVPP1708 & $17,625 \mathrm{~b}-\mathrm{e}$ \\
\hline & AVPP1714 & 8,667 ef \\
\hline & PBC 435 & $16,573 \mathrm{~b}-\mathrm{e}$ \\
\hline & & $P<0.001$ \\
\hline
\end{tabular}

${ }_{\mathrm{z}}$ Means within a column followed by the same letter do not significantly differ at $\alpha=0.05$ using Tukey's honestly significant difference. significantly influenced pollen activity. The main effect of month was the single greatest contributor to the variability observed for pollen activity $(\mathrm{MS}=9.3)$, pollen concentration $\left(\mathrm{MS}=1.1 \times 10^{10}\right)$, pollen germination $(\mathrm{MS}=$ 112.4 ), and pollen viability ( $\mathrm{MS}=0.6$ ), whereas heat treatment was the greatest contributor to variability in pollen tube length (MS = 40,764).

Despite significant interaction effects, the pollen germination rate was lower in June compared with April for all entries (Fig. 3). The greatest pollen germination rates were for the untreated AVPP $1108(36 \%)$, the $45^{\circ} \mathrm{C}$ heat-treated and untreated AVPP0701 (34\% and $30 \%$, respectively), and the untreated $\mathrm{PBC}$ 370 (32\%) during April (Fig. 3). Pollen germination rate during June was generally similar across treatments and typically lower than $10 \%$ (Fig. 3). During April, pollen germination rate was typically higher for the untreated compared with the two heat treatments (Fig. 3).

Differences in pollen tube length were generally greatest between treatments, compared with month or entries, despite significant interaction effects (Fig. 4). Across entries and treatments, the average pollen tube length was $22.8 \mu \mathrm{m}$ in April and $19.5 \mu \mathrm{m}$ in June, whereas average pollen tube length was 42 $\mu \mathrm{m}$ for untreated, $11.1 \mu \mathrm{m}$ for $45^{\circ} \mathrm{C}$, and 10.1 $\mu \mathrm{m}$ for $50^{\circ} \mathrm{C}$ heat treatments (Fig. 4). The entry AVPP1108 had the longest pollen tube length under untreated conditions during April $(126 \mu \mathrm{m})$, followed by untreated AVPP1327 during June (103 $\mu \mathrm{m})$ (Fig. 4). 


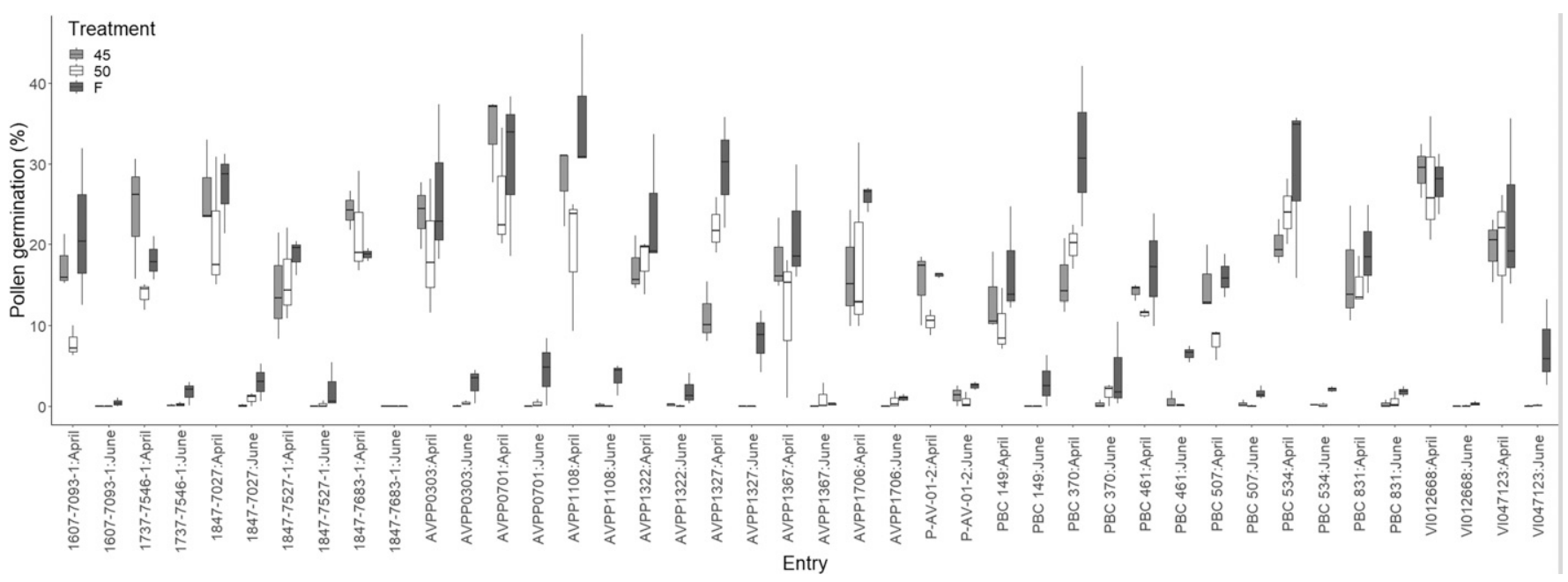

Fig. 3. Percent pollen germination of 21 pepper (Capsicum annuum) entries heat treated with either 45 or $50{ }^{\circ} \mathrm{C}$ or untreated ( $\mathrm{F}$; control) during the months of April (cooler) and June (hotter). Box plots with medians within the first and third quartile of another box plot do not significantly differ at $\alpha=0.05$.

association $\left(R^{2}=0.53\right)$ between pollen viability and pollen activity (Fig. 11).

\section{Discussion}

Accurate selection is among the first requirements in successful breeding for a particular trait. Heat tolerance is a complex phenotype consisting of several component traits, each of which likely has complex inheritance patterns (De la Peña et al., 2011; Driedonks et al., 2016; Hanson et al., 2002; Hedhly, 2011). The response of pepper to high temperatures at the vegetative (generally seedling) (Ali et al., 2020; Feng, et al., 2019; Li et al., 2015; Rajametov et al., 2021; Usman et al., 2015; Zhai et al., 2016) and reproductive (Aloni et al., 2001; Erikson and Markhart, 2002; Motamedi et al., 2018; Polowick and Sawhney, 1985; Usman et al., 1999) stages during the growing season have previously been explored. Among the most important component traits of heat tolerance in fruiting crops, such as pepper, involve reproductive tissues, especially pollen (Dane et al., 1991; Giorno et al., 2013; Hedhly et al., 2009). Strategies to accurately phenotype pollen traits in pepper have been developed (Aloni et al., 2001; Gajanayake et al., 2011; Reddy and Kakani, 2007). However, the developed strategies are often tedious and time-consuming in addition to evaluating a limited number of pollen grains (typically $\approx 100$ ), making them potentially inaccurate. To overcome these limitations, Heidmann et al. (2016) proposed the use of IFC in screening for pollen development and viability under heat stress in pepper and other crops. However, there is a need to expand on this work and conduct additional experiments to confirm the applicability of using IFC to assess pollen in pepper.

To develop and validate the use of IFC for evaluating pollen traits in pepper under heat stress conditions, three independent experiments were conducted. The most appropriate flower developmental stage to conduct IFC was determined. Stages 3,4 , and
5 (Fig. 1) were found to best combine high pollen concentration with high pollen activity in two pepper (a heat-tolerant and a heat-sensitive) entries (Table 1). Erikson and Markhart (2002) evaluated the sensitivity of different flower development stages of pepper to high temperature stress and found that flowers at both early and late stages of development were more sensitive to heat stress. The authors found that flowers just before anthesis contained mature pollen grains, and, when exposed to high temperatures, a significant reduction in pollen tube growth and guidance, but not viability, was observed (Erikson and Markhart, 2002). Using IFC, viable pollen that will germinate (active pollen), viable pollen that will not germinate (inactive pollen), and inviable pollen can be distinguished. Young flowers (stages 1 and 2) and flowers just before anthesis (stage 3) were found to have the higher proportion of active pollen using IFC (Table 1). However, as expected, pollen concentration, pollen that has dehisced from the anthers, was lowest for

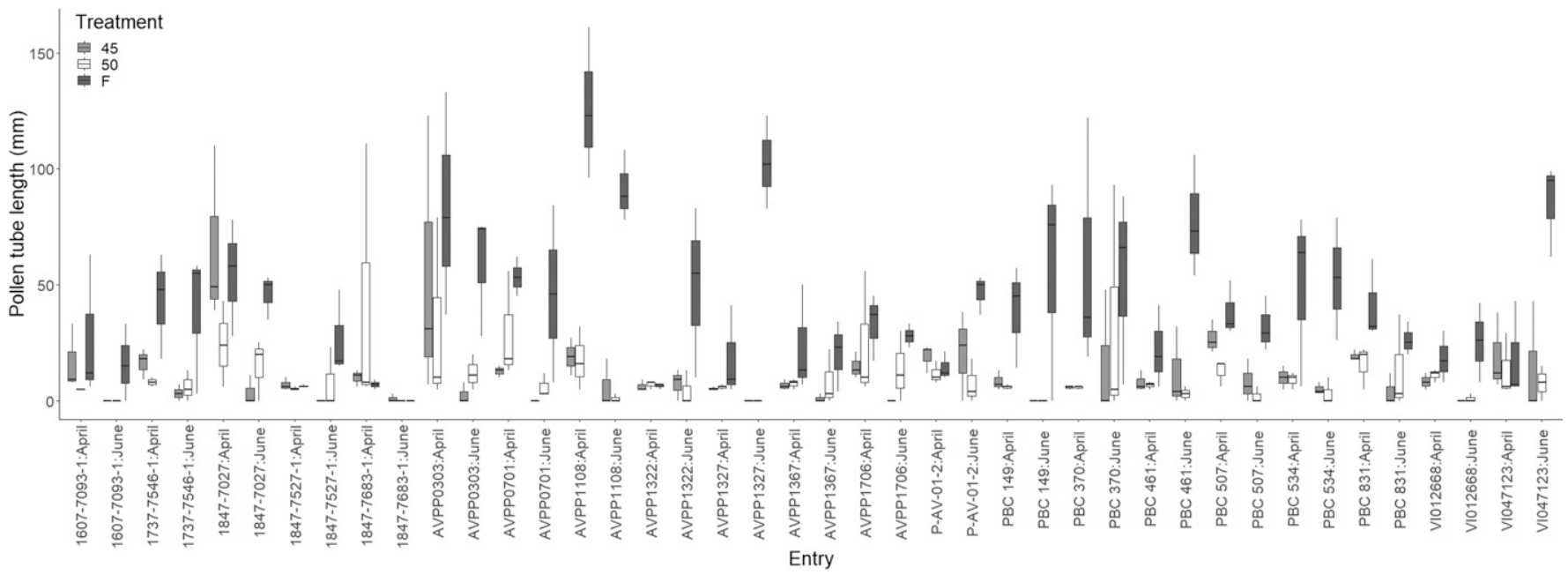

Fig. 4. Pollen tube length $(\mu \mathrm{m})$ of 21 pepper (Capsicum annuum) entries heat treated with either 45 or $50{ }^{\circ} \mathrm{C}$ or untreated (F; control) during the months of April (cooler) and June (hotter). Box plots with medians within the first and third quartile of another box plot do not significantly differ at $\alpha=0.05$. 


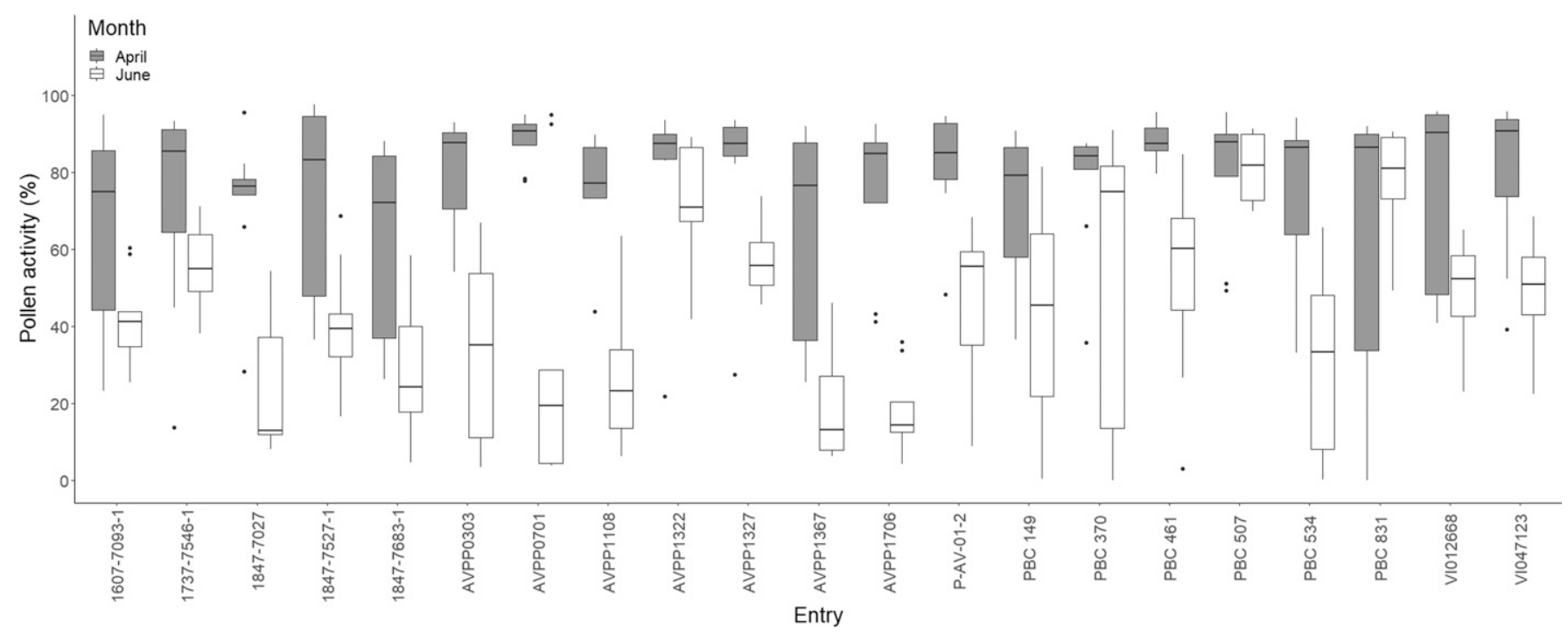

Fig. 5. Percent of active pollen of 21 pepper (Capsicum annuum) entries during April (cooler) and June (hotter) averaged across heat treatments of 45 , $50{ }^{\circ} \mathrm{C}$ or untreated (control). Box plots with medians within the first and third quartile of another box plot do not significantly differ at $\alpha=0.05$.

stage 2 and higher before and after anthesis (Table 1). Pollen concentrations in pepper have not been previously reported, to the best of our knowledge, but in tomato, pollen concentrations have been found to range from 694,000 grains per flower under ideal conditions to 367,000 grains per flower under heat stress conditions (Pressman et al., 2002), which is considerably higher than what was found in this study. Differences in pollen concentration between these studies could be due to the use of different methods to determine pollen number and that the studies were conducted in two species with different mating systems (Cruden, 2000).

The critical temperature for determining heat tolerance using IFC to assess pollen traits in our experiment was $50^{\circ} \mathrm{C}$. We found significant declines in pollen activity at all temperatures greater than $47^{\circ} \mathrm{C}$, and heat treatment at $55^{\circ} \mathrm{C}$ resulted in the lowest pollen activity. Similarly, Heidmann et al. (2016) heat treated pollen using gradient polymerase chaine reaction between 40 and $60^{\circ} \mathrm{C}$ for $15 \mathrm{~min}$ and found that pepper pollen viability was significantly reduced at temperatures greater than $48^{\circ} \mathrm{C}$ using IFC. Erikson and Markahrt (2002) exposed pepper plants at varying stages of flower development to different durations of heat treatment at $33{ }^{\circ} \mathrm{C}$ and found significant reductions in fruit set when flowers were exposed during early developmental stages. Similarly, pollen germination and pollen tube length of pepper has been found to be reduced at temperatures between 30 and $35^{\circ} \mathrm{C}$, with the maximum temperatures to observe pollen germination typically $\approx 40^{\circ} \mathrm{C}$, although variation among entries was reported (Gajanayake et al., 2011; Reddy and Kakani, 2007). Differences in temperatures reported to be associated with reduced pollen viability are likely due to the use of different entries with differing levels of heat tolerance as well as methodology of heat treatment. Exposing plants to high temperature results in an apparent greater effect on the floral tissues compared with exposing only the pollen, as was done here. However, the critical temperatures reported previously (Erikson and Markhart, 2002; Gajanayake et al., 2011; Reddy and Kakani, 2007) are within the range of optimal growth and develop (Aloni et al., 2001; Polowick and Sawhney, 1985; Wubs et al., 2009).

The interaction of heat treatment and entry for pollen concentration was expected. Variation among entries for pollen concentration has previously been reported for other crops, such as in wild and cultivated tomato (Solanum spp.) (Paupière et al., 2017), in

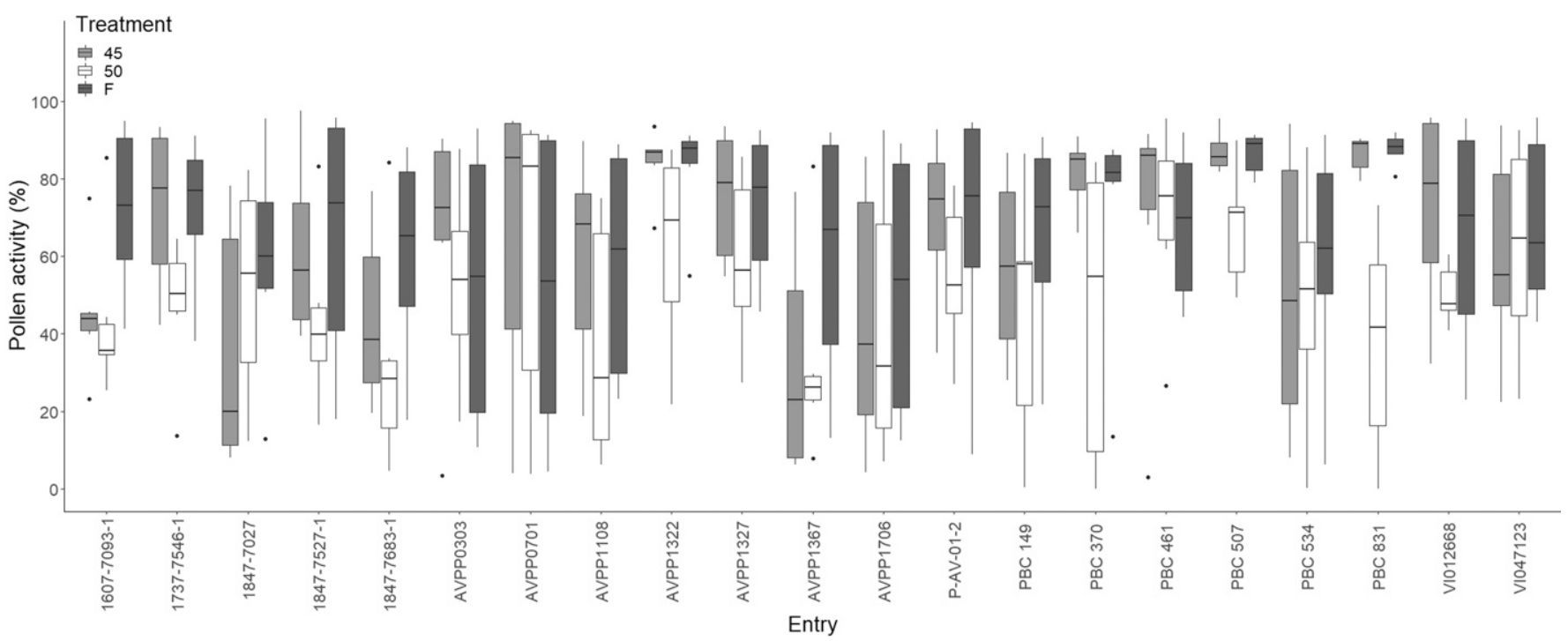

Fig. 6. Percent of active pollen of 21 pepper (Capsicum annuum) entries heat treated with either 45 or $50^{\circ} \mathrm{C}$ or untreated (F; control) averaged across April (cooler) and June (hotter). Box plots with medians within the first and third quartile of another box plot do not significantly differ at $\alpha=0.05$. 


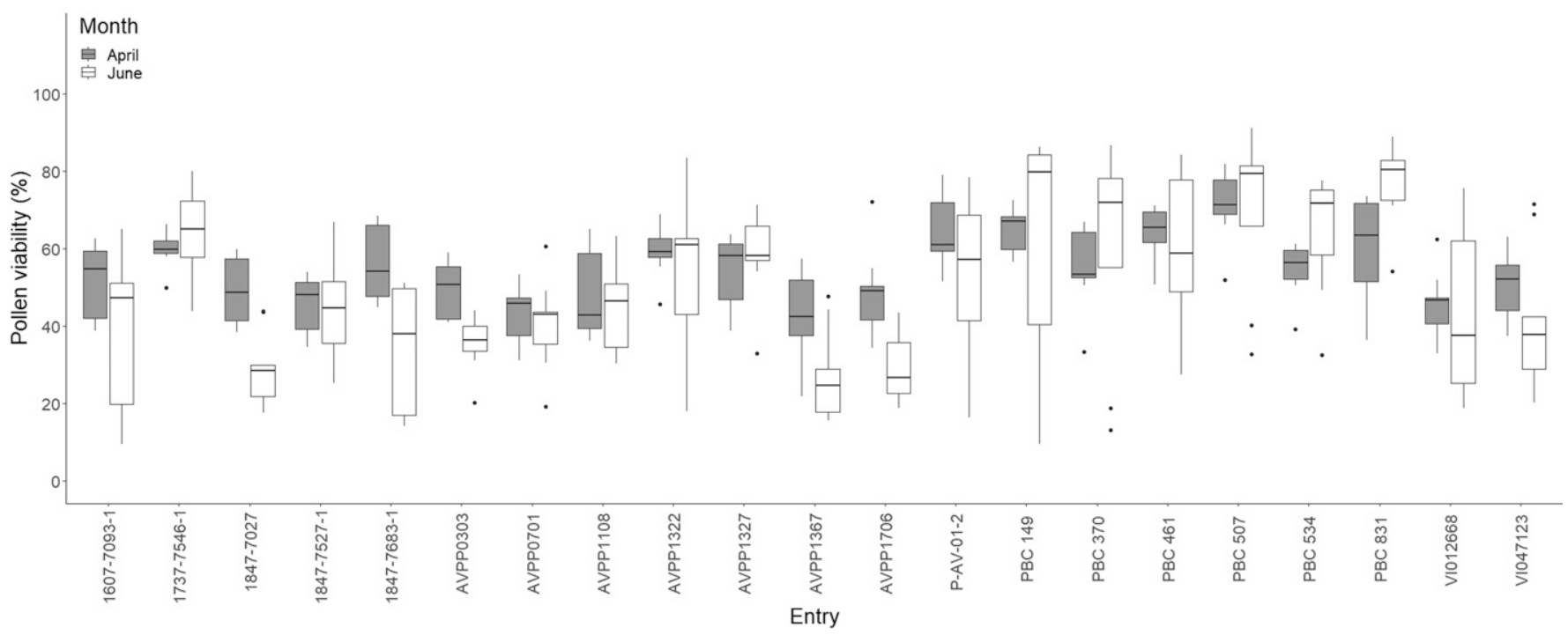

Fig. 7. Pollen viability of 21 pepper (Capsicum annuum) entries during April (cooler) and June (hotter) averaged across heat treatments of 45 , $50{ }^{\circ} \mathrm{C}$, and untreated (check). Box plots with medians within the first and third quartile of another box plot do not significantly differ at $\alpha=0.05$.

numerous legumes (Astragalus spp., Hedysarum spp., Lathyrus ochroleucus, Lupinus spp., Oxytropis spp., Thermopsis rhombifolia, and Vicia americana) (Vonhof and Harder, 1995) and in hazelnut assessed using IFC (Ascari et al., 2020). Furthermore, it is logical that pollen concentration would not be solely influenced by heat treatment because the heat treatment was imposed on mature flowers collected from plants grown under ideal conditions and not during flower production. We hypothesize that variation in heat treatment by entry for pollen concentration is an artifact of natural variation that occurs among flowers within an entry. This is supported by the pollen concentration of AVPP1704, which had among the highest pollen concentrations under heat treatment of $55^{\circ} \mathrm{C}$ but among the lowest when heat treated at 44 or $47^{\circ} \mathrm{C}$.

For the validation experiment, growing month was the largest contributor to variability observed for every trait we measured, with the exception of pollen tube length. During our experiment, temperatures, particularly night temperatures, were generally higher in June compared with April. In an earlier experiment, we also found that the growing environment was a major factor in cross- and self-pollination success rate among Capsicum species, although heat treatment at $38^{\circ} \mathrm{C}$ was the greatest contributor to variability (Lin et al., 2021). The effect of growing environment on both female and male reproductive organs has been previously reported in pepper (Erikson and Markhart, 2002; Gajanayake et al., 2011; Reddy and Kakani, 2007), with high

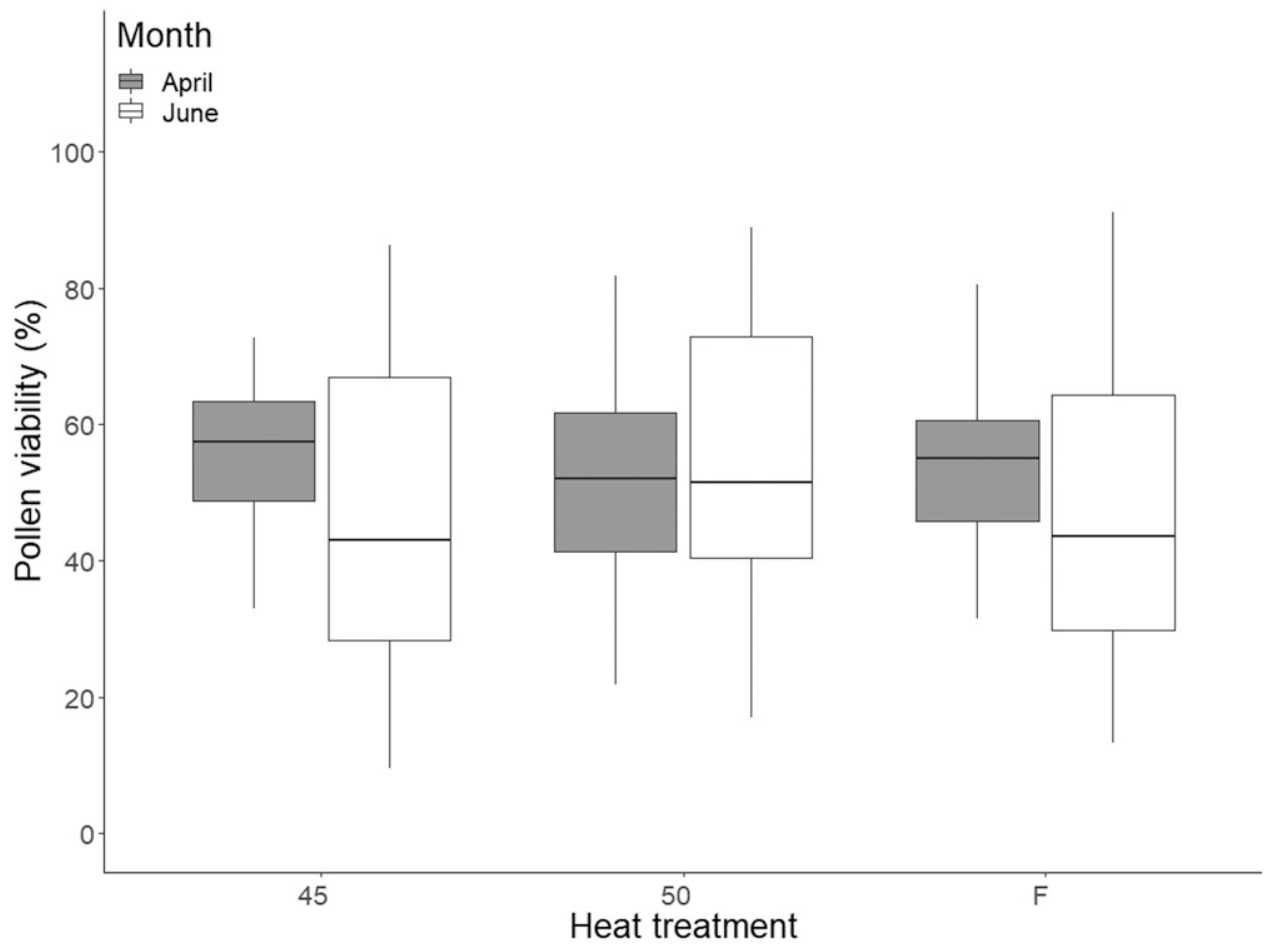

Fig. 8. Pollen viability determined using flowers heat treated with either 45 or $50^{\circ} \mathrm{C}$ or untreated (check) during April (cooler) and June (hotter) averaged across 21 pepper (Capsicum annuum) entries. Box plots with medians within the first and third quartile of another box plot do not significantly differ at $\alpha=0.05$. 


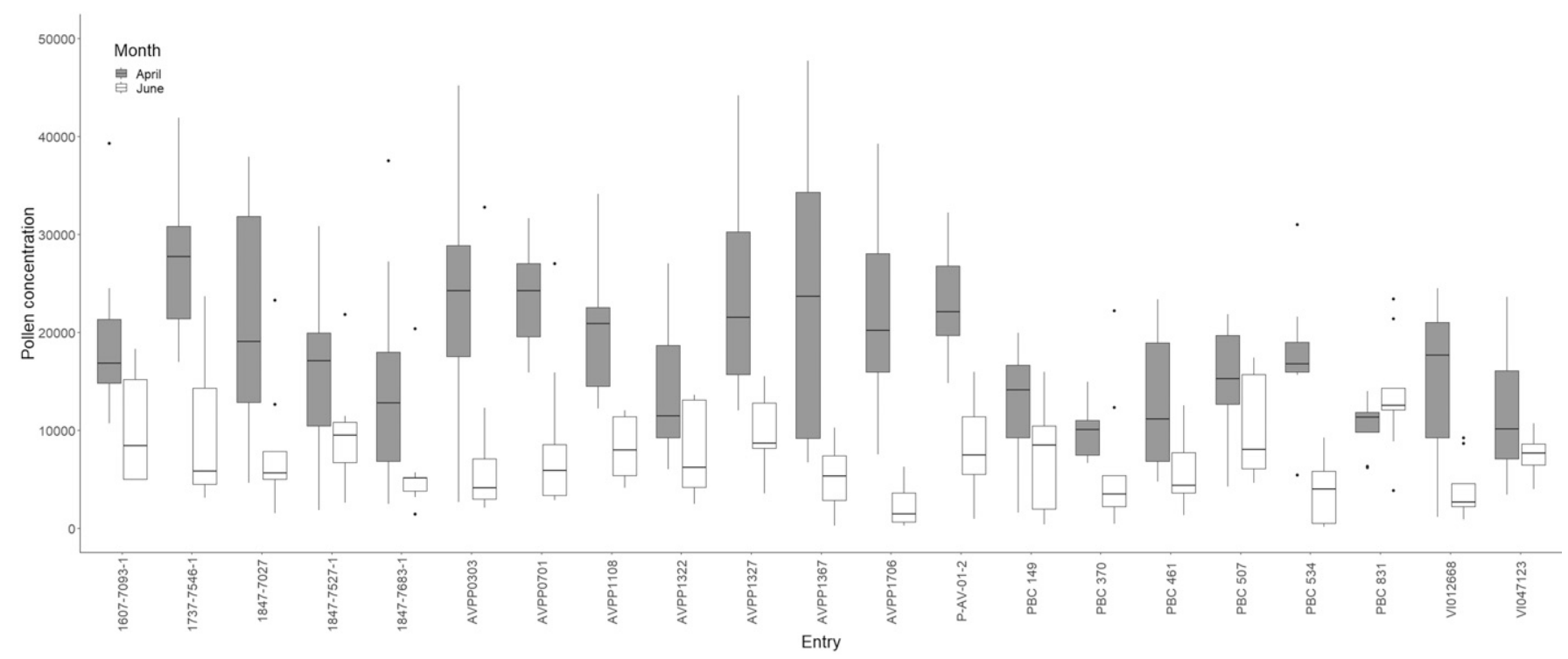

Fig. 9. Pollen concentration of 21 pepper (Capsicum annuum) entries during April (cooler) and June (hotter) averaged across heat treatments of $45,50{ }^{\circ} \mathrm{C}$, and untreated (check). Box plots with medians within the first and third quartile of another box plot do not significantly differ at $\alpha=0.05$.

temperatures typically resulting in reduced floral organ viability. It is known that higher yields result when daily air temperature ranges between 18 and $32{ }^{\circ} \mathrm{C}$ during fruit set. During April, temperatures exceeded $32^{\circ} \mathrm{C}$ between 11:00 AM and 4:00 PM on most days but were otherwise generally within the optimal range for pepper. Conversely, temperatures frequently exceeded $32^{\circ} \mathrm{C}$ by as early as 8:00 AM and did not go below $32^{\circ} \mathrm{C}$ until after 6:00 PM during June. Temperatures were never below $24^{\circ} \mathrm{C}$ during June and were often 27 to $29^{\circ} \mathrm{C}$ during the night, whereas night temperatures in April were generally lower than $25^{\circ} \mathrm{C}$. The more optimal growing conditions in April clearly contributed to the better performance for nearly all traits among the entries. However, heat treatment was still highly effective at differentiating heat-tolerant and heat-sensitive entries, which was supported by our previous experiments (Lin et al., 2021).

Sources of heat tolerance have been previously reported in pepper (Feng et al., 2019; Gajanayake et al., 2011; Usman et al., 2015). Two novel sources of heat tolerance, PBC 507 and $\mathrm{PBC}$ 831, were identified through these experiments. The pollen activity of PBC 507 and PBC 831 were less affected by heat treatment and growing month compared with the other entries in this experiment. Further research needs to be conducted to confirm the heat tolerance in these two lines, but using IFC to identify sources of heat tolerance has been previously reported in tomato (Luria et al., 2019). Given the high level of throughput and accuracy of using IFC, there is potential for this technology to be used in breeding programs both by assessing diverse germplasm, such as core collections, and for phenotyping segregating populations for heat tolerance.

The typical method for assessing pollen viability is through staining and the use of microscopy to determine the proportion of viable and inviable pollen grains in a given sample. This method is tedious, time-consuming, and potentially inaccurate because a limited number of pollen grains are typically

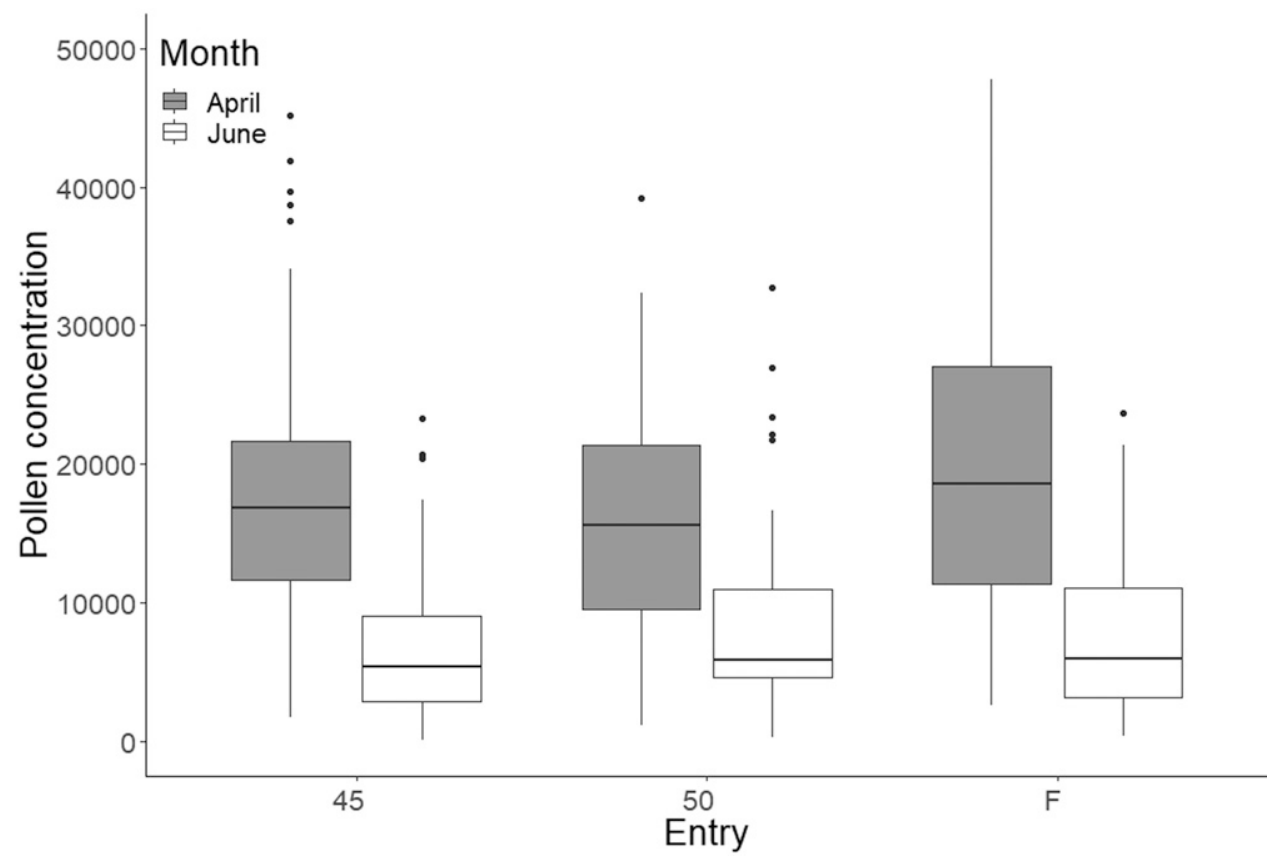

Fig. 10. Pollen concentration using flower heat treated with either 45 or $50^{\circ} \mathrm{C}$ or untreated (check) during April (cooler) and June (hotter) averaged across 21 pepper (Capsicum annuum) entries. Box plots with medians within the first and third quartile of another box plot do not significantly differ at $\alpha=0.05$. 


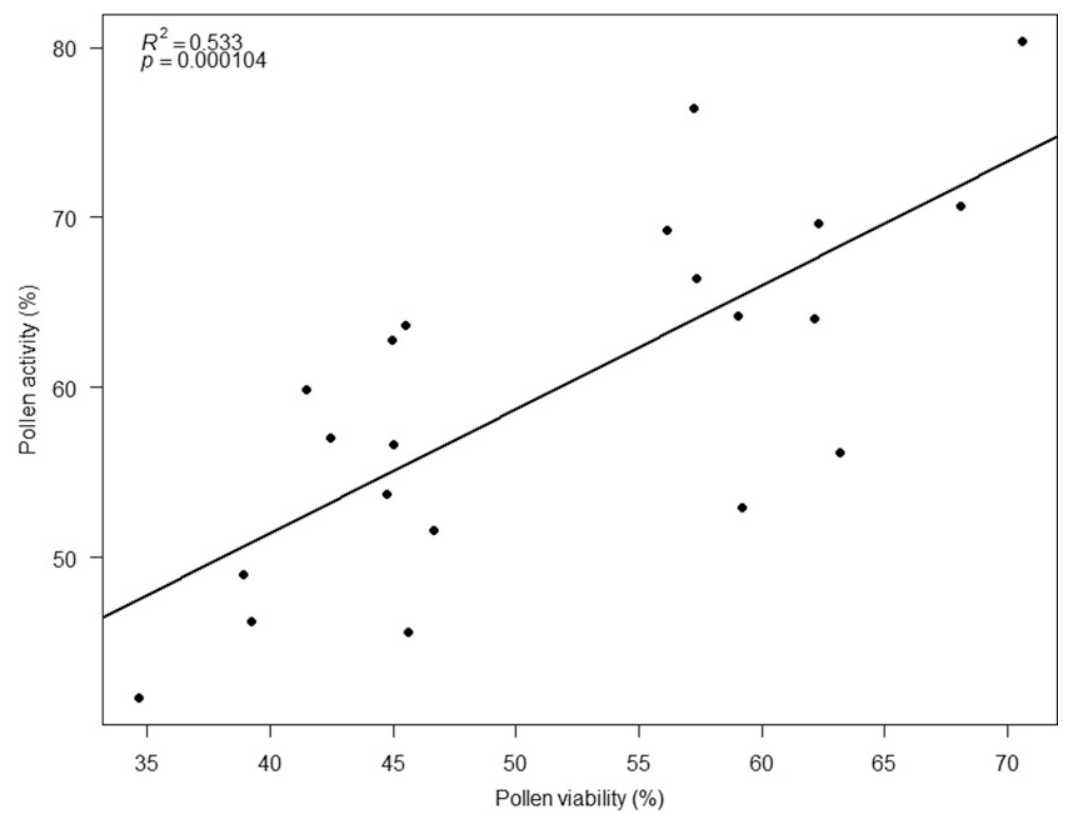

Fig. 11. Correlation between pollen activity determined by impedance flow cytometry (IFC) and pollen viability assessed through staining of 21 pepper (Capsicum annuum) entries averaged across month (April and June) and heat treatment (untreated control and heat treatment at 45 and $50{ }^{\circ} \mathrm{C}$ ).

evaluated, which may not be a representative sample given that flowers can produce copious amounts of pollen. To overcome this, the use of IFC has been proposed to be a more efficient and accurate method of assessing pollen traits in pepper and other crops. A significant and positive correlation between pollen viability using staining and pollen activity using IFC was found during this experiment. This finding supports the use of IFC in assessing pollen quality in pepper under heat stress conditions as a more efficient method than pollen staining, being accurate and faster to conduct. However, the correlation between pollen viability and activity in our experiment were lower than those reported by Heidmann et al. (2016). The reason for the differences in correlation are likely because we evaluated far more entries with varying levels of heat tolerance in our experiment. Additionally, it is possible that by evaluating $\approx 100$ pollen grains per sample when assessing viability using staining that the accuracy could be lower, which would result in lower correlations.

\section{Literature Cited}

Ali, M., I. Muhammad, S.U. Haq, M. Alam, A.M Khattak, K. Akhtar, H. Ullah, A. Khan, G. Lu, and Z.H. Gong. 2020. The CaChiVI2 gene of Capsicum annuum L. confers resistance against heat stress and infection of Phytophthora capsici. Front. Plant Sci. 11:219, https://doi.org/10.3389/ fpls.2020.00219.

Aloni, B., M. Peet, M. Pharr, and L. Karni. 2001. The effect of high temperature and high atmospheric $\mathrm{CO}_{2}$ on carbohydrate changes in bell pepper (Capsicum annuum) pollen in relation to its germination. Physiol. Plant. 112(4):505-512, https:// doi.org/10.1034/j.1399-3054.2001.1120407.x.

Ascari, L., V. Cristofori, F. Macrì, R. Botta, C. Silvestri, T. De Gregorio, E.S. Huerta, M. Di Berardino, S. Kaufmann, and C. Siniscalco.
2020. Hazelnut pollen phenotyping using labelfree impedance flow cytometry. Front. Plant Sci. 11:1935, https://www.frontiersin.org/article/ 10.3389/fpls.2020.615922.

Azzarello, E., R. Masi, and S. Mancuso. 2012. Electrochemical impedance spectroscopy, p. 205-223. In: A. Volkov (ed.). Plant electrophysiology: Methods and cell electrophysiology. Springer-Verlag. Heidelberg, Germany, https://doi.org/10.1007/ 978-3-642-29119-7_9.

Bosland, P.W. and E.J. Votava. 2012. Peppers: Vegetable and spice capsicums. 2nd ed. CAB International, Wallingford, UK.

Canonge, J., M. Philippot, C. Leblanc, P. Potin, and M. Bodin. 2020. Impedance flow cytometry allows the early prediction of embryo yields in wheat (Triticum aestivum L.) microspore cultures. Plant Sci. 300:110586, https://doi.org/ 10.1016/j.plantsci.2020.110586.

Cheung, K., S. Gawad, and P. Renaud. 2005. Impedance spectroscopy flow cytometry: On-chip label-free cell differentiation. Cytometry A 65: 124-132, https://doi.org/10.1002/cyto.a.20141.

Cruden, R.W. 2000. Pollen grains: Why so many? Plant Syst. Evol. 222:143-165, https://doi.org/ 10.1007/BF00984100.

Dane, F., A.G. Hunter, and O.L. Chambliss. 1991. Fruit set, pollen fertility, and combining ability of selected tomato genotypes under high temperature field conditions. J. Amer. Soc. Hort Sci. 116(5):906-910, https://doi.org/10.21273/ JASHS.116.5.906

De la Peña, R.C., A.W. Ebert, P.A. Gniffke, P. Hanson, and R.C. Symonds. 2011. Genetic Adjustment to Changing Climates: Vegetables, p. 396-410. In: S. Shyam, J. Robert, L. Jerry, H. Lotze-Campen, and E. Anthony (eds.). Crop adaptation to climate change. John Wiley \& Sons, Hoboken, NJ

Driedonks, N., I. Rieu, and W.H. Vriezen. 2016. Breeding for plant heat tolerance at vegetative and reproductive stages. Plant Reprod. 29:67-79, https://doi.org/10.1007/s00497-016-0275-9.

Erikson, A.N. and A.H. Markhart. 2002. Flower developmental stage and organ sensitivity of bell pepper (Capsicum annuum L.) to elevated temperature. Plant Cell Environ. 25(1):123-130, https://doi.org/10.1046/j.0016-8025.2001.00807. $\mathrm{x}$.

Food and Agriculture Organization of the United Nations (FAO). 2019. FAOSTAT statistics database. Food and Agriculture Organization, Rome, Italy. <http://www.fao.org/faostat/en/ \#data/QCL>.

Feng, X.H., H.X. Zhang, M. Ali, W.X. Gai, G.X. Cheng, Q.H. Yu, S.B. Yang, X.X. Li, and Z.H Gong. 2019. A small heat shock protein CaHsp25.9 positively regulates heat, salt, and drought stress tolerance in pepper (Capsicum annuum L.). Plant Physiol. Biochem. 142:151-162, https://doi. org/10.1016/j.plaphy.2019.07.001.

Gajanayake, B., B.W. Trader, K.R. Reddy, and R.L. Harkess. 2011. Screening ornamental pepper cultivars for temperature tolerance using pollen and physiological parameters. HortScience 46(6): 878-884, https://doi.org/10.21273/HORTSCI.46. 6.878.

Giorno, F., M. Wolters-Arts, C. Mariani, and I. Rieu. 2013. Ensuring reproduction at high temperatures: The heat stress response during anther and pollen development. Plants 2(3):489-506, https:// doi.org/10.3390/plants2030489.

Halikowski-Smith, S. 2015. In the shadow of a pepper-centric historiography: Understanding the global diffusion of capsicums in the sixteenth and seventeenth centuries. J. Ethnopharmacol. 167:64-77, https://doi.org/10.1016/j.jep.2014.10. 048.

Hanson, P.M., J.-T. Chen, and G. Kuo. 2002. Gene action and heritability of high-temperature fruit set in tomato line CL5915. HortScience 37(1): 172-175, https://doi.org/10.21273/HORTSCI.37. 1.172 .

Hedhly, A. 2011. Sensitivity of flowering plant gametophytes to temperature fluctuations. Environ. Exp. Bot. 74:9-16, https://doi.org/10.1016/ j.envexpbot.2011.03.016.

Hedhly, A., J.I. Hormaza, and M. Herrero. 2009. Global warming and sexual plant reproduction. Trends Plant Sci. 14:30-36, https://doi.org/ 10.1016/j.tplants.2008.11.001.

Heidmann, I. and M. Di Berardino. 2017. Impedance flow cytometry as a tool to analyze microspore and pollen quality. Methods Mol. Biol. 1669: 339-354, https://doi.org/10.1007/978-1-4939-72 86-9_25.

Heidmann, I., G. Schade-Kampmann, J. Lambalk, M. Ottiger, and M. Di Berardino. 2016. Impedance flow cytometry: A novel technique in pollen analysis. PLoS One 11(11):e0165531, https://doi.org/10.1371/journal.pone.0165531.

Heslop-Harrison, J., Y. Heslop-Harrison, and K.R. Shivanna. 1984. The evaluation of pollen quality, and a further appraisal of the fluorochromatic (FCR) test procedure. Theor. Appl. Genet. 67: 367-375, https://doi.org/10.1007/BF00272876.

Impe, D., J. Reitz, C. Köpnick, H. Rolletschek, A. Börner, A. Senula, and M. Nagel. 2020. Assessment of pollen viability for wheat. Front. Plant Sci. 10:1588, https://doi.org/10.3389/fpls.2019. 01588.

Kenyon, L., P. Hanson, S. Kumar, S.L. Shih, M.H. Hsieh, H.Y. Chen, S.F. Lu, Y.Y. Wang, S.W. Lin, and Y.H. Cheng. 2017. Treatment for cleaning small seed lots of tomato and pepper seeds of surface contamination with viroids The World Vegetable Center. 15 Aug. 2021. $<$ https://worldveg.tind.io/record/74053? $\ln =\mathrm{en}>$.

Kron, P. and B.C. Husband. 2015. Distinguishing $2 \mathrm{~N}$ gamete nuclei from doublets in pollen using flow cytometry and pulse analysis. Cytometry A 87:943-957, https://doi.org/10.1002/cyto.a.22696.

Li, T., X. Xu, Y. Li, H. Wang, Z. Li, and Z. Li. 2015. Comparative transcriptome analysis reveals 
differential transcription in heat-susceptible and heat-tolerant pepper (Capsicum annum L.) cultivars under heat stress. J. Plant Biol. 58:411-424, https://doi.org/10.1007/s12374-015-0423-z.

Lin, S.W., T.H. Lin, Y.W. Wang, and D.W. Barchenger. 2020. High throughput pollen phenotyping using impedance flow cytometry for heat tolerance selection in pepper (Capsicum spp.). HortScience 55(9):S156 (abstr.).

Lin, T.H., S.W. Lin, Y.W. Wang, M. van Zonneveld, and D.W. Barchenger. 2021. Growing environment and heat treatment effects on intra- and interspecific pollination in chile pepper (Capsicum spp.). Agronomy (Basel) 11(7):1275, https://doi.org/10.3390/ agronomy11071275.

Luria, G., N. Rutley, I. Lazar, J.F. Harper, and G. Miller. 2019. Direct analysis of pollen fitness by flow cytometry: Implications for pollen response to stress. Plant J. 98:942-952, https:// doi.org/10.1111/tpj.14286.

Mercado, J.A.R.F.-M. and M.A. Quesadac. 1994. In vitro germination of pepper pollen in liquid medium. Scientia Hort. 57(4):273-281, https:// doi.org/10.1016/0304-4238(94)90110-4.

Motamedi, M., M. Haghighi, and A. Goli. 2018. Physiological changes of sweet and hot peppers in vegetative and reproductive growth stages treated by $\mathrm{Ca}$ and $\mathrm{H}_{2} \mathrm{O}_{2}$ under unforeseen heat stresses. Scientia Hort. 249:306-313, https:// doi.org/10.1016/j.scienta.2019.01.040.

Paupière, M.J., P. van Haperen, I. Rieu, R.G.F. Visser, Y.M. Tikunov, and A.G. Bovy. 2017. Screening for pollen tolerance to high temperatures in tomato. Euphytica 213:130, https://doi. org/10.1007/s10681-017-1927-z.
Polowick, P.L. and V.K. Sawhney. 1985. Temperature effects on male fertility and flower and fruit development in Capsicum annuum L. Scientia Hort. 25(2):117-127, https://doi.org/10.1016/03 04-4238(85)90083-4.

Pressman, E., H. Moshkovitch, K. Rosenfeld, R. Shaked, B. Gamleil, and B. Aloni. 1998. Influence of low night temperatures on sweet pepper flower quality and the effect of repeated pollinations, with viable pollen, on fruit set. J. Hort. Sci. Biotechnol. 73(1): 131-136, https://doi.org/10.1080/14620316.1998. 11510955.

Pressman, E., M.M. Peet, and D.M. Pharr. 2002. The effect of heat stress on tomato pollen characteristics is associated with changes in carbohydrate concentration in the developing anthers. Ann. Bot. 90(5):631-636, https://doi. org/10.1093/aob/mcf240.

R Core Team. 2020. R: A language and environment for statistical computing. <https://www. R-project.org/>.

Rajametov S., E.Y. Yang, M.C. Cho, S.Y. Chae, and H.B. Jeong. 2021. Morpho-physiological response to heat stress during seedling stage and interrelation with agronomical traits in pepper (Capsicum annuum L.) cultivars differing in heat tolerance (In press), https://doi.org/ 10.21203/rs.3.rs-120894/v1.

Reddy, K.R. and V.G. Kakani. 2007. Screening Capsicum species of different origins for high temperature tolerance by in vitro pollen germination and pollen tube length. Scientia Hort. 112(2):130-135, https://doi.org/10.1016/j.scienta. 2006.12.014.
Sanders, D.C., H.J. Kird, and C. van der Brink. 1980. Growing degree days in North Carolina. North Carolina Ag. Ext. Serv., Sparta, NC.

Sun, T. and H. Morgan. 2010. Single-cell microfluidic impedance cytometry: A review. Microfluid. Nanofluidics 8:423-443, https://doi.org/10.1007/ s10404-010-0580-9.

Usman, I.S., A.S. Mamat, H.S.Z. Syed Mohd, H.S. Aishan, and R.A. Anuar. 1999. The nonimpairment of pollination and fertilization in the abscission of chilli (Capsicum annuum $\mathrm{L}$. Var. Kulai) flowers under high temperature and humid conditions. Scientia Hort. 79(12):1-11, https://doi.org/10.1016/S0304-4238 (98)00171-X.

Usman, M.G., M.Y.Rafii, M.R. Ismail, M.A. Malek, and M.A.Latif.2015.Expressionoftargetgene Hsp 70 and membrane stability heat tolerance in chili pepper. J. Amer.Soc.Hort.Sci.140(2):144-150,https://doi.org/ 10.21273/JASHS.140.2.144.

Vonhof, M.J. and L.D. Harder. 1995. Size-number trade-offs and pollen production by papilionaceous legumes. Amer. J. Bot. 82(2):230-238, https://doi.org/10.1002/j.1537-2197.1995.tb11 491.x.

Wubs, A.M., E. Heuvelink, and L.F.M. Marcelis. 2009. Abortion of reproductive organs in sweet pepper (Capsicum annuum L.): A review. J. Hort. Sci. Biotechnol. 84:467-475, https://doi. org/10.1080/14620316.2009.11512550.

Zhai, Y., M. Guo, H. Wang, J. Lu, J. Liu, C. Zhang, Z. Gong, and M. Lu. 2016. Autophagy, a conserved mechanism for protein degradation, responds to heat, and other abiotic stresses in Capsicum annuum L. Front. Plant Sci. 7:131, https://doi.org/10.3389/fpls.2016.00131. 